\title{
Um estudo de caso \\ sobre o Português como Língua de Herança (PLH) nas cidades de Suzuka e Sakai, Japão
}

\author{
Tábata Quintana Yonaha \\ PPGLA - Universidade de Brasília \\ tabataqy@hotmail.com \\ Yuki Mukai \\ Universidade de Brasília \\ yuki@unb.br
}

\section{Resumo}

Este artigo é a conversão de alguns capítulos da dissertação que consistiu em um estudo de caso coletivo sobre as crenças e as ações de brasileiros imigrantes no Japão acerca do Português como Língua de Herança (doravante PLH). Os objetivos desta investigação foram identificar as crenças dos participantes sobre o aprendizado do PLH e suas ações em relação à manutenção do PLH, bem como analisar as relações estabelecidas com base nestas. O aporte teórico da investigação foi o de Língua de Herança, de PLH e também da pesquisa em crenças e ações. O aporte metodológico foi o da pesquisa qualitativa de caráter interpretativista, guiado pela interpretação contextual de investigação em crenças em um estudo de caso viabilizado pelo uso dos seguintes instrumentos de coleta de dados: observação direta, notas de campo, entrevista semiestruturada e questionário misto. Os resultados obtidos indicam uma estreita relação entre as crenças e as ações dos participantes no processo de ensino-aprendizagem do PLH dos seus filhos e, portanto, há convergências e divergências quanto à atribuição de valores e objetivos em relação ao aprendizado desta $\mathrm{LH}$, à continuidade do estudo e, por fim, as implicações do monolinguismo das mães e o bilinguismo dos filhos.

Palavras-chave: Português como Língua de Herança. Crenças e ações. Imigração Brasil- Japão.

\section{Abstract}

This article is a primer on converting some chapters from the dissertation based on collective case study regarding beliefs and actions of Brazilian 
immigrants in Japan about 'Portuguese as a Heritage Language' (PLH). The research aimed at identifying the participant's beliefs on learning the PLH and their actions concerning its maintenance, as well as analyzing the relations established among their beliefs and actions on PLH. The theoretical framework that allowed the study was the 'Heritage Language' (LH) and PLH studies, as well as the research on beliefs and actions. Therefore, the methodology was the qualitative research carried by interpretative approach, feasible on beliefs contextual research approach and used the following data collection instruments: observations, field notes, semi-structured interviews and mixed written questionnaire. The results showed a close relation between the beliefs and action of the participants in the learning and teaching process of PLH from their children, thereby resulting in common grounds and beam divergences of beliefs on assigning different values and objectives on the LH learning, continuity of study and, finally, the implications of mother's monolingualism and their children's bilingualism.

Keywords: Portuguese as a Heritage Language. Beliefs and actions. BrazilJapan immigration.

\section{Contextualização e justificativa: onde e por que o PLH?}

O crescimento do número de estudos e discussões acerca do PLH é notório em países onde a imigração brasileira ocorre com maior expressividade, tais como EUA, Alemanha, Suíça e vários outros países da Europa. É também crescente o número de projetos e organizações não governamentais de apoio à língua-cultura brasileira que se unem e promovem iniciativas que asseguram a preservação da língua de herança não apenas entre brasileiros, mas também auxiliam a divulgar nossa língua pelos outros continentes afora. Diante desse crescente panorama, interessei-me, sobretudo, em compreender em quais contextos o português é mantido e quais as ações dirigidas para que obtivessem um resultado satisfatório no aprendizado, em especial no Japão, nas cidades de Suzuka e Sakai. A imagem a seguir ilustra o perfil da diáspora brasileira de acordo com o último censo de 2014 do Ministério das Relações Exteriores: 
Um estudo de caso sobre o PLH...

Figura 1: Estimativa oficial da diáspora brasileira.

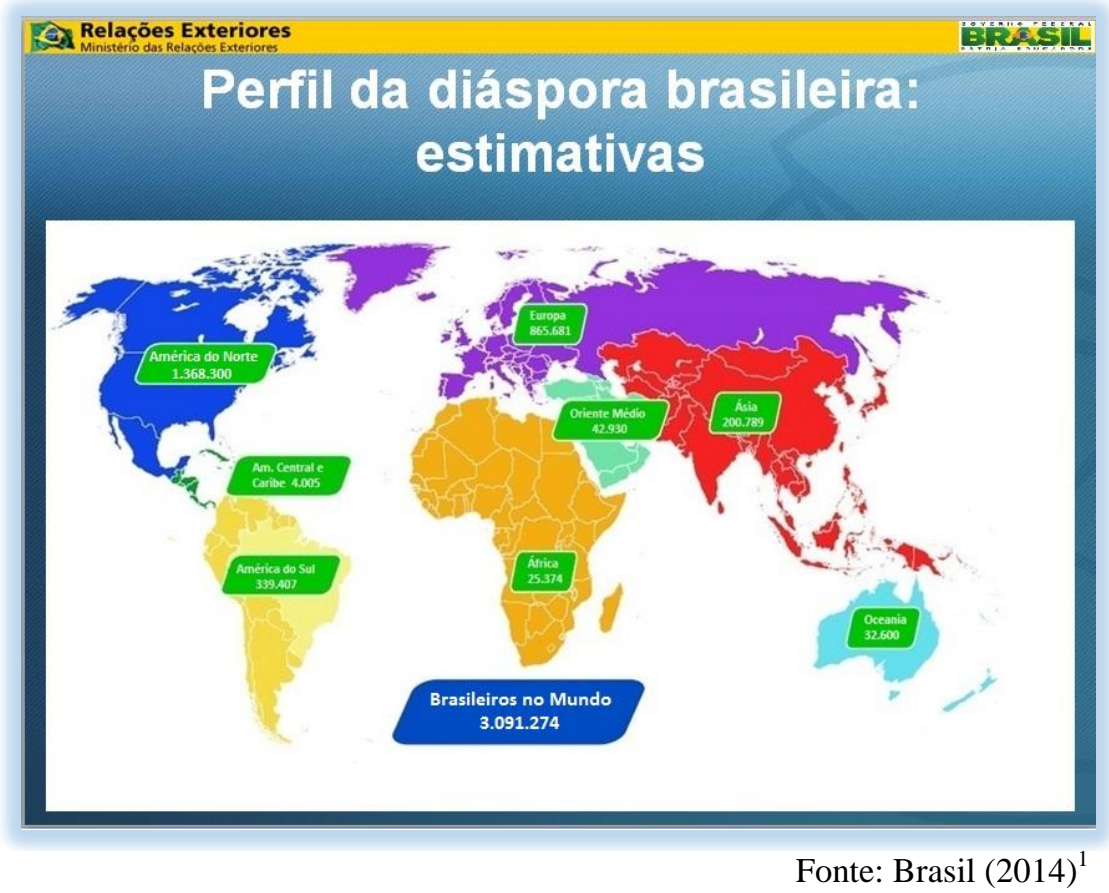

\section{Português como língua de herança}

O Português como Língua de Herança caracteriza-se, geralmente, pelo ensino-aprendizagem da língua-cultura ${ }^{2}$ portuguesa pelos filhos de imigrantes. Conforme apontado por Mendes (2012), os brasileiros que residem no exterior tendem a manter as práticas de uso do português em ambiente familiar, ainda que de forma assistemática e irregular, enquanto seus filhos têm cada vez mais contato com a "língua-cultura hospedeira" por meio da escola, do convívio social

\footnotetext{
${ }^{1}<\mathrm{http}: / /$ www.brasileirosnomundo.itamaraty.gov.br/acomunidade/estimativas-populacionais-das-comunidades/estimativaspopulacionais-brasileiras-mundo-2014/Estimativas\%20RCN\%202014.jpg> ${ }^{2}$ A indissociabilidade da língua de cultura está em consonância com o defendido por Kramsch (1998).
} 
dentre outros ambientes. É comum, portanto, a criação de escolas de PLH no contexto dos imigrantes brasileiros não somente no Japão, mas onde a diáspora brasileira apresente um número expressivo destes, e no caso do território nipônico há aproximadamente 186 mil brasileiros segundo dados recentes do Itamaraty (2013). Ainda de acordo com a autora supracitada:

O processo de ensino-aprendizagem de PLH deve ser capaz de desenvolver nos alunos as capacidades de tradução, de movimento e deslize entre as línguas-culturas em contato, permitindo que cada aprendiz construa o seu próprio lugar na língua, com suas próprias ferramentas e possibilidades. A eles deve ser permitido construírem os seus próprios modos de representação, de aproximação e pertencimento (MENDES, 2012, p. 30).

Lico (2011), ao abordar o crescente fluxo de brasileiros para países como Estados Unidos, Japão, Itália e tantos outros que oferecem melhores oportunidades socioeconômicas, relata que há uma consciência em manter vivo no seio familiar dessas famílias o vínculo com as origens e as culturas brasileiras:

Essa consciência, manifestada pelo desejo de que os filhos criem ou mantenham vínculos afetivos com os familiares residentes no Brasil e pela necessidade de que haja entendimento entre as partes e bom trânsito no ambiente social quando visitam o País, tem motivado mais e mais famílias a procurar maneiras de proporcionar o aprendizado da língua portuguesa e da riqueza da cultura brasileira a seus descendentes. Vale destacar que esse movimento é dramaticamente maior entre os brasileiros que emigraram, temporária ou permanentemente, em situação regular e que tem, portanto, melhores condições sócio-econômicas [sic] para compreender essa situação e tornar possiveis suas escolhas (LICO, 2011, p. 1).

Percebemos por meio das leituras relacionadas às línguas de herança que a família tem papel fundamental no processo educativo por ser a fonte de insumo principal da língua. Contudo, as representações do governo brasileiro perante as autoridades japonesas, 
neste caso particular, tais como quatro embaixadas e consulados e outras representações políticas brasileiras, constituem mediadores basilares na divulgação e na projeção do PLH. Apesar da expressividade numérica brasileira emigratória em direção ao Japão, bem como de suas relações de cooperação financeira (projetos nacionais de grande porte como a siderúrgica Usiminas (MG), a Cenibra de celulose (MG), o estaleiro Ishibras (RJ), dentre outros), intercâmbio cultural e diplomático (120 anos de amizade Japão-Brasil), a comunidade brasileira no Japão ainda não foi contemplada de forma substanciosa com as iniciativas culturais e educativas do MRE.

Além das políticas públicas, é importante mencionar a política linguística familiar quando do ensino-aprendizagem de PLH, pois a relação que os imigrantes, neste caso os pais (familiares), ${ }^{3}$ têm com a língua dominante, ou seja, a língua falada no país onde residem, é fundamental. Se, por um lado, há dificuldade de os pais aprenderem a segunda língua, por outro lado, seus filhos avançam rapidamente na aquisição do novo código linguístico. Desse modo, há uma inversão de poder na dinâmica familiar, conforme Mota (2004, p. 153) aponta:

Nas relações familiares, os filhos ganham ainda maior poder quando passam a assumir funções primordiais à sobrevivência dos pais, tais como a de porta-voz, tradutor e intérprete, principalmente em transações ocorridas em agências de serviços públicos. Muitas vezes quer se afirmar a "normalidade" do fato, mas sempre se deixa passar uma sensação de desconforto nos seus relatos.

A dinâmica familiar pode ser seriamente afetada pela aquisição, ou pela não aquisição, da L2 tanto pelos pais como pelos filhos. A situação linguística de algumas famílias tende a ser configurada, conforme esclarece Valdés (2001), com as gerações mais novas apresentando domínio pleno da língua majoritária e dificuldades ou até mesmo o não aprendizado de sua LH. Lee e Shin (2008) confirmam tal

${ }^{3}$ Creio ser importante destacar que, neste estudo de caso, com essas famílias, a escolha de mães como participantes foi uma consequência natural na pesquisa, haja vista que durante o período de observação direta e entrevista na escola de PLH somente mães compareceram e, ainda, quando menciono "pais" esclareço que o protagonismo é majoritariamente das mães. 
proposição ao encontrarem dados similares com falantes de LH coreana residentes nos EUA:

No cenário típico, a primeira geração fala a língua nativa, enquanto a segunda geração é bilíngue em algum grau, seguida pela terceira geração falante da língua majoritária. No entanto, recentemente um número crescente de comunidades de língua minoritária está passando por uma completa mudança de linguagem dentro das duas gerações sem uma geração bilíngue entre elas (Wiley, 2001). Esta mudança acelerada cria grandes problemas de comunicação, como pais e filhos que vivem na mesma família e não entendem uns aos outros. (LEE; SHIN, 2008, p. 159, tradução nossa).

Neste estudo de caso, tive acesso à primeira geração de imigrantes, representada pelas mães, e seus filhos representando a segunda geração, portanto não cabe aqui a generalização da proposição do bilinguismo de acordo com as gerações, mas podemos visualizar o crescimento da língua majoritária em detrimento da LH, haja vista que as participantes mães acreditam ser importante a proficiência de português para seus filhos, em especial para manter a comunicação entre eles e também com os familiares do Brasil.

Desse modo, percebemos o quão valioso pode ser o oferecimento de insumo de qualidade da LH, bem como o processo de nutrição de língua-cultura dos pais para que possam transmitir aos filhos essa herança. Busquei, portanto, compreender neste estudo as ações de promoção e ambientação do PLH em território japonês pelos participantes para contextualizar tal vivência e como tal experiência, exposta por meio de suas crenças, influencia o aprendizado da LH em questão.

\section{Breve panorama sobre o ensino-aprendizagem de PLH no Japão}

Até o momento da tessitura deste artigo ainda não havia uma política definida no Japão sobre o ensino-aprendizagem de LH, seja de português ou de qualquer outra língua que imigrantes tenham levado ao solo nipônico. O governo japonês garante o acesso e o ensino da língua japonesa aos estrangeiros. Contudo, as LH não estão entre as 
línguas que merecem destaque e ou incentivo de estudo. Apesar disso, é possível avaliar que há uma boa representatividade do ensinoaprendizado do Português como Língua Estrangeira (PLE) na graduação de quatro universidades japonesas, sendo elas a Universidade de Quioto, a Universidade de Línguas Estrangeiras de Tóquio, a Universidade Sophia (em Tóquio) e a Universidade de Osaka.

O Quadro 1 mostra o número de estudantes colegiais que aprendem português, dentre outras línguas, nas escolas públicas. A pesquisa foi realizada pelo Ministério da Educação, Ciência e Tecnologia do Japão (MEXT) no período referente ao ano de 2013 ao início de 2016.

Quadro 1. Línguas estrangeiras estudadas em escolas japonesas (à exceção do inglês)

\begin{tabular}{|c|c|c|c|c|c|}
\hline Posição & Língua utilizada & Pública & Privada & Nacional & Total \\
\hline 1 & & & & & \\
\hline 2 & Chinês & 11.697 & 7.370 & 39 & 19.106 \\
\hline 3 & Coreano & 8.551 & 2.642 & 17 & 11.210 \\
\hline 4 & Alemão & 1.673 & 1.997 & 21 & 3.584 \\
\hline 5 & Espanhol & 2.588 & 736 & 59 & 3.383 \\
\hline 6 & Russo & 628 & 167 & & 795 \\
\hline 7 & Italiano & 263 & 93 & & 356 \\
\hline $\mathbf{8}$ & Português & $\mathbf{1 2 8}$ & $\mathbf{1 3}$ & & $\mathbf{1 4 1}$ \\
\hline 9 & Persa & 31 & 35 & & 66 \\
\hline 10 & Vietnamita & 24 & 22 & & 46 \\
\hline
\end{tabular}

Fonte: YONAHA, 2016, adaptação do Ministério da Educação, Ciência e Tecnologia do Japão (MEXT, 2016)

Diante da representatividade do português nas áreas supracitadas, é plausível inferir que a língua portuguesa vem sendo moderadamente reconhecida nas redes educacionais japonesas. No entanto, para fins de delimitação do trabalho, foquei somente nos projetos de PLH e não pude visitar escolas japonesas que ofereçam português como língua estrangeira. À ocasião, visitei três dos diversos 
projetos brasileiros voluntários sobre PLH no Japão, sendo eles: o Projeto Girassol, o Projeto Aquarela e o Projeto Construir/Artel. Por limitações financeiras e de tempo, haja vista a curta duração da estaa, concentrei-me somente no último projeto mencionado e realizei entrevistas com as mães, bem como a observação direta e a aplicação de questionários para obtenção dos registros e posterior análise de dados. Para fins de conhecimento e visualização do cenário da área em questão, relato brevemente as visitas de campo dos outros projetos:

\subsection{Projeto Girassol - cidade de Suzuka}

Em 18 de julho de 2015 conheci o Projeto Girassol, um grupo de voluntários que nas manhãs de sábado ensina português aos filhos de imigrantes brasileiros residentes no Japão, especificamente na cidade de Suzuka, desde aproximadamente o ano de 2009. Há quatro níveis de proficiência em português: iniciante, intermediário I e II e gramática. As salas são geralmente compostas por crianças matriculadas em escolas japonesas e possuem níveis de proficiência distintos: há aqueles que já dominam o código linguístico satisfatoriamente e aperfeiçoam as habilidades mais avançadas, como os que estão no processo da alfabetização e articulação fonética.

O fenômeno Code Switch (alternância do código linguístico) é constante durante a observação das aulas. Muitos alternam a língua portuguesa com a japonesa como a seguinte frase: "Nande de quem é isso?" (O quê? de quem é isso) ou "É para deixar só o enpitsu" (É para deixar só o lápis) e diversos outros episódios similares. Uma das principais preocupações da professora responsável pela turma e também pela coordenadora do projeto é o caso das crianças double limited (duplamente limitados), ou seja, aquelas que não podem comunicar-se de forma satisfatória nem na língua japonesa nem na língua materna - o português.

\subsection{Projeto Aquarela}

Iniciado em 2009, na cidade de Suzuka, o projeto visa a ajudar crianças matriculadas nas escolas japonesas que encontram dificuldades de aprendizado, seja por não conhecerem o idioma japonês seja pela falta de compreensão do sistema adotado pelas 
escolas japonesas. Além disso, auxilia crianças que já finalizaram o equivalente ao segundo ciclo do ensino fundamental e desejam ingressar no ensino médio $(K o ̂ k o ̂)$. A rede voluntária do Projeto Aquarela é a mesma do Projeto Girassol, todavia o objetivo deste projeto é auxiliar os alunos do ensino fundamental e do ensino médio das instituições de ensino japonesas, e a participação não é restrita a brasileiros, havendo também participantes de outras nacionalidades, tais como paquistaneses, indonésios e chineses, por exemplo.

As aulas de reforço ou orientação têm a duração de aproximadamente sete horas e trinta minutos, de segunda a sexta-feira. Alunos matriculados no ensino fundamental tem carga horária menor, pois as aulas ocorrem após o término do horário escolar regular. As aulas são totalmente gratuitas e os professores são qualificados para ministrar as seguintes disciplinas: japonês, matemática, estudos sociais e ciências. A língua de mediação dependerá da nacionalidade do estudante, mas os professores geralmente se comunicam em português, inglês, espanhol e, preferencialmente, em japonês. O projeto visa não somente ao suporte aos alunos, mas também oferece apoio aos pais, seja por meio de tradução de documentos, esclarecimento de tarefas de casa, acompanhamento em reuniões, aconselhamentos e até a regularização de matrículas na prefeitura da cidade.

\subsection{Projeto Construir/Artel - região de Osaka}

É uma iniciativa que desenvolve e promove o PLH na região de Osaka, na cidade de Sakai. Surgiu em 2008, ainda sob a organização do Projeto Construir, e em 2012 a Oficina de Arte Educação e Letramento (Artel) uniu-se ao projeto sob a coordenação de Luzia Tanaka, formada em Educação Artística e Pedagogia pela UFMT (Convênio Brasil-Japão). É o único projeto educacional no Estado de Osaka a oferecer apoio para os brasileirinhos matriculados nas escolas japonesas. Os grupos de alunos frequentam as aulas de português após o horário escolar japonês. Geralmente são alunos na faixa etária de 6 a 14 anos de idade, e frequentemente os pais, em especial as mães, acompanham tais atividades.

A professora Luzia Tanaka informou em entrevista que há diferentes níveis de proficiência dos alunos e que todos se comunicam na língua de preferência, na qual se sentem mais confortáveis, seja 
português seja japonês, embora a maioria utilize a língua japonesa para mediação nas aulas. Outro ponto importante compartilhado foi a da rejeição inicial de alguns alunos ao português, ocasionando alguns conflitos identitários entre eles, haja vista que alguns participantes, apesar de brasileiros, não falavam português e não se consideravam brasileiros.

Desse modo, o projeto trabalha sob uma abordagem flexível, acolhendo inicialmente os alunos e despertando-lhes o interesse, a curiosidade e o senso de pertencimento ao Brasil e, posteriormente, e de forma natural, o aprendizado do PLH. Este aprendizado ocorre a partir de construções e interações com sentido real, das próprias experiências dos alunos, e a elaboração da aula e material didático parte do interesse dos alunos, de modo que se sintam motivados e interessados pela língua-cultura brasileira. Além do ensino do português como LH, há também dois voluntários japoneses que auxiliam no reforço das disciplinas das escolas japonesas.

É importante ressaltar que o projeto realiza diversas atividades culturais fora do ambiente formal da sala de aula, tais como visita a museus, piqueniques, janelas de contação de histórias, acampamentos com a participação dos pais, apresentações de dança, festivais, dentre outros. O engajamento familiar merece destaque, pois o elo entre o projeto e os familiares tem fortalecido o crescimento e a manutenção do projeto. Os participantes desta pesquisa são, na maioria, mães ativas no projeto e seus filhos. Salientamos que muitos pais que buscam o PLH para seus filhos necessitam da língua como meio de comunicação entre eles, tendo em vista não dominarem o código linguístico japonês e, consequentemente, veem-se impossibilitados de interação na língua nativa dos filhos.

O projeto supracitado foi reconhecido em uma das revistas brasileiras de circulação nacional, a Revista Alternativa, sobre o Festival de Outono organizado pela comunidade de Sakai, que reuniu pais, crianças, brasileiros em geral e outros voluntários do projeto. Outro importante reconhecimento foi o do jornal japonês Asahi Shinbun, sob o título de "Um local de apoio à realização de sonhos: o alívio de não estar sozinho” (夢の手助け学びの場: 一人じやない安 心育む: Yume no tedasuke manabinoba: hitorijanai anshin hagukumu), disponível na seção de anexos deste trabalho. O ensino de PLH no 
Japão tem sido reconhecido recentemente tanto pela comunidade brasileira nesse país, ao desenvolver projetos que incentivem e promovam nossa língua-cultura, como pela comunidade japonesa.

Em outras palavras, a sociedade japonesa começa a (re)conhecer tais ações e dá sinais de receptividade para com a realidade multicultural de seus imigrantes, embora o cenário ainda esteja longe do ideal. A pesquisa de crenças e ações dos participantes sobre o PLH busca entender quais relações são estabelecidas, e a partir destas esperamos compreender o PLH no contexto emigratório brasileiro no Japão. A seguir, apresento um breve diálogo sobre a relação entre crenças e ações ante o ensino-aprendizado de PLH vivenciado pelos participantes.

\section{As relações entre as crenças e as ações dos participantes em relação ao PLH}

A relação entre as crenças e as ações dos participantes ${ }^{4}$ do estudo foi norteada pela análise das crenças contextualizadas, dentro do local de ação dos participantes, conforme já asseverado por Abrahão (2006). É importante esclarecer que compreendo crenças como "concepções, formais e informais, de caráter temporário ou permanente, acerca do processo ensino-aprendizagem sob uma dimensão global, que incorpora o contexto social, político, cultural e de natureza dialógica, onde as experiências e, consequentemente a linguagem, são socialmente construídas (YONAHA, 2016, p. 42)”.

Há três maneiras possíveis de entender tal relação ao retomarmos o aporte teórico lançado por Barcelos (2006): 1) a relação de causa e efeito, na qual as crenças influenciam diretamente as ações;

\footnotetext{
${ }^{4}$ Para a realização deste estudo foram selecionadas três mães e seus respectivos filhos, todos matriculados em um curso de português como LH na região de Osaka, Japão. As crenças e as ações dos participantes foram coletadas, identificadas e analisadas por meio de observação direta, entrevista semiestruturada e aplicação de questionário misto, com itens fechados e abertos, e as notas de campo foram registradas no diário da pesquisadora. Tudo foi triangulado e analisado de modo que sustentasse as interpretações mencionadas neste artigo.
} 
2) interativa, em que crenças e ações se influenciam mutuamente; 3) uma relação complexa que nos apresenta um conjunto de discursos e práticas distinto e, portanto, pressupõe interações multidimensionais, pessoais e contextuais.

Diante disso, apresento algumas dessas relações estudadas no contexto dos familiares e dos aprendentes do PLH nos projetos de LH das cidades de Suzuka e Sakai, dispostos da seguinte maneira: na subseção 4.1, a expectativa do aprendizado do PLH e a convergência e a divergência de ações; a seguir, na seção 4.2, configurações de funcionamento do PLH. Além disso, na seção 4.3, trato das implicações do monolinguismo das mães e do bilinguismo de seus filhos.

\subsection{A expectativa do aprendizado do PLH e a convergência e a divergência de ações}

Ao relacionar as crenças das participantes mães (doravante PM) e dos participantes filhos (doravante PF) quanto à motivação do aprendizado do PLH, é possível afirmar que a expectativa de aprendizado do português como LH é fortemente marcada na fala das participantes mães, mas de tom moderado na fala dos filhos. Ao dizer isso não excluo ou deixo de analisar as expectativas dos filhos, ao contrário, pois eles também participaram da pesquisa quanto à trajetória de aprendizado do PLH. Todavia, o desejo de transmissão da língua-cultura brasileira parte, preponderantemente, das mães brasileiras, consideradas as principais promotoras de tal desenvolvimento.

Nesse sentido, propus-me a analisar o direcionamento das crenças das PM em relação às de seus filhos, pois, conforme institui Barcelos (2007), nem sempre agimos de acordo com o que pensamos, e os pontos de tensão (hot spots) indicados por Woods (1996) podem ilustrar tal dissonância entre as crenças e as ações entre os participantes. Para atingir tal objetivo, recorremos às falas que evidenciam tais expectativas das PM e dos PF no questionário, mas também às notas provenientes das observações diretas.

Dentre os participantes, os registros da PM1 e seu filho, o PF1, sugerem dados importantes, pois, de acordo com as observações realizadas, parece haver uma confluência na expectativa da PM1 e do 
PF1 em aprofundar seus conhecimentos na LH. Durante a observação direta realizada por esta pesquisadora, o PF1 foi o único a, espontaneamente, iniciar um diálogo e fazer perguntas diversas sobre o Brasil à pesquisadora. Possivelmente um dos excertos mais curtos dentre as falas dos participantes, mas também extremamente significativo, foi o seguinte diálogo:

$\left[30^{5}\right]^{6}$ Pesquisadora: Você pretende voltar ao Brasil um dia? PF1: CLARO!

Tal resposta foi dita em tom de obviedade, como se o retorno ao país dos pais fosse indubitável, enquanto os outros $\mathrm{PF}$ demonstraram neutralidade ou até mesmo pouco interesse pelo retorno. Além disso, o PF1 é conhecido no projeto como um dos alunos mais interessados e com espírito de liderança em relação às atividades e às iniciativas referentes ao PLH. Uma microcena representativa de tal disposição em aprender foi a organização de uma simulação eleitoral brasileira de 2014 entre os alunos, na qual o PF1 foi eleito por unanimidade entre os participantes, ou ainda, entre os pequenos "eleitores", como presidente e representante do grupo. Inferimos que tal aprendizagem existente no projeto extrapola o âmbito linguístico, buscando envolver os alunos em todas as nuanças que permeiam a sociedade brasileira.

Os dados sugerem que exemplos como esse ocorrem quando há uma convergência mínima entre as crenças das mães e as dos filhos quanto a essa aprendizagem e a relação de prestígio da língua na família. Em outras palavras, se dentro do planejamento linguístico da família o PLH é valorizado e representa uma ferramenta de comunicação e estudo, possivelmente os filhos compartilharão em algum nível dessas crenças e, consequentemente, terão ações positivas em direção a isso. Partindo de tal perspectiva, elaboramos o Quadro 2 com base nos excertos das falas das PM e dos PF a fim de sintetizar tal relação.

${ }^{5}$ Os excertos aqui enumerados correspondem à numeração descrita na dissertação que originou a tessitura deste artigo.

${ }^{6}$ As regras de transcrição foram baseadas na obra de Marcuschi (2003). 
Quadro 2. Expectativa de aprendizado e direcionamento das crenças

\begin{tabular}{|c|c|c|}
\hline Participante mãe & Participante filho & Direção das crenças \\
\hline $\begin{array}{l}\text { PM1 [31] } \\
\text { quando vorque } \\
\text { eles não terão muitas } \\
\text { dificuldades no ensino } \\
\text { escolar (Q, pergunta } \\
\text { XV, PM1) }\end{array}$ & $\begin{array}{lr}\text { PF1 Motivação: } & {[32]} \\
\text { Sim, porque tenho } \\
\text { vontade de morar no } \\
\text { Brasil (Q, } \\
\text { pergunta } & \mathrm{XF}) \\
\text { Importância: }[33] & {[\ldots]} \\
\text { Porque posso } & \text { me } \\
\text { comunicar } & {[\mathrm{em}} \\
\text { português] com meus } \\
\text { parentes do Brasil }(\mathrm{Q}, \\
\text { PF1, pergunta XI) }\end{array}$ & $\begin{array}{l}\text { Convergente: Tanto a } \\
\text { PM quanto o PF } \\
\text { parecem convergir } \\
\text { quanto à motivação e as } \\
\text { expectativas } \\
\text { aprendizado do PLH, } \\
\text { que é o retorno ao } \\
\text { Brasil e a importância } \\
\text { da língua para a } \\
\text { continuidade } \\
\text { estudos. dos } \\
\end{array}$ \\
\hline $\begin{array}{l}\text { PM2 [34] Não tenho } \\
\text { expectativas porque as } \\
\text { oportunidades de } \\
\text { aprender o português } \\
\text { são poucas (Q, pergunta } \\
\text { XV, PM2) }\end{array}$ & $\begin{array}{l}\text { PF2 Motivação: }[35] \\
\text { Sim, porque minha mãe } \\
\text { fala em português } \\
\text { comigo e também } \\
\text { porque faço aula de } \\
\text { português (Q, PF2, } \\
\text { pergunta } \\
\text { Importância: } \\
\text { porque consigo falar } \\
\text { [em português] com os } \\
\text { meus parentes que } \\
\text { moram no Brasil (Q, } \\
\text { PF2, pergunta XI). }\end{array}$ & $\begin{array}{l}\text { Divergente: A PM2, em } \\
\text { resposta ao } \\
\text { questionário, mostra-se } \\
\text { com poucas } \\
\text { expectativas em relação } \\
\text { ao aprendizado das } \\
\text { filhas, no entanto, a PF2 } \\
\text { informa que a língua é } \\
\text { importante para manter } \\
\text { os vínculos familiares } \\
\text { não apenas com a mãe, } \\
\text { mas com os familiares } \\
\text { residentes no Brasil. }\end{array}$ \\
\hline $\begin{array}{l}\text { PM2 [37] Não tenho } \\
\text { expectativas porque as } \\
\text { oportunidades } \\
\text { aprender o português } \\
\text { são poucas (Q, pergunta } \\
\text { XV, PM2) }\end{array}$ & $\begin{array}{l}\text { PF3 Motivação: }[38] \\
\text { porque falo com minha } \\
\text { mãe em português e } \\
\text { também faço aula }(\mathrm{Q}, \\
\text { PF3, pergunta } \mathrm{X}) \\
\text { Importância: } \\
\text { porque consigo falar } \\
\begin{array}{l}\text { [em português] com os } \\
\text { brasileiros. (Q, PF3, } \\
\text { pergunta XI) }\end{array}\end{array}$ & $\begin{array}{l}\text { Divergente: Apesar de a } \\
\text { PM2 ter poucas } \\
\text { expectativas quanto ao } \\
\text { aprendizado de PLH da } \\
\text { filha, esta demonstra } \\
\text { motivação r para } \\
\text { aprender português para } \\
\text { comunicar-se não } \\
\text { apenas com a mãe ou } \\
\text { familiares, mas alega } \\
\text { ser importante para } \\
\text { manter o vínculo com } \\
\text { os brasileiros, de modo } \\
\text { geral. }\end{array}$ \\
\hline
\end{tabular}

Fonte: YONAHA, 2016, p. 101 
Pela leitura do quadro acima, inferimos que o esforço em manter e/ou criar oportunidades de uso real da LH é essencial para seu desenvolvimento. Contudo, também é preciso compreender de que forma os alunos podem ser motivados para tal aprendizagem e, principalmente, quais os objetivos e os benefícios de tal processo. Os falantes da LH não se apropriam somente da língua, mas esta apresenta-se com uma função social que deve ser estimulada e valorizada para que se desenvolva de forma exitosa. Montrul (2012) assevera que se a língua não for utilizada além do círculo familiar, se não for ouvida e falada em outros ambientes, os falantes não verão seu valor, e isso está implicado no status sociopolítico de uma língua, ou seja, os valores simbólicos do capital linguístico e a relação de investimento, afetando, portanto, as atitudes e as crenças referentes a essa língua.

Conforme Moroni (2015), a LH, seja no ambiente familiar seja no formal, está intimamente ligada às necessidades do aluno. A falta de uso da língua e de momentos que propiciem tal uso pode levar à falta de interesse e de domínio e, consequentemente, desvincular-se da língua-cultura totalmente. Inferimos, desse modo, que o papel familiar é fundamental em todo esse processo, em especial o papel da conscientização de pais e filhos sobre a importância da vivência na língua e sobre a motivação extra para os aprendizes de LH, conforme apontado por Montrul (2012).

Apesar de a PM2 não ter revelado expectativas sobre a aprendizagem do PLH de suas filhas, estas revelam interesse e possuem objetivos específicos de uso da língua. Se em um contexto em que as crenças são divergentes há estímulo suficiente para a aprendizagem, perguntamo-nos como seriam tais resultados se o cenário fosse ideal: pais conscientes e estimuladores da $\mathrm{LH}$ e filhos interessados e dispostos ao processo amparados por políticas públicas profícuas. Compreendemos que não se trata meramente da convergência ou da divergência das crenças dos participantes - há uma rede orgânica de fatores envolvidos no processo:

a) o contexto pode ou não propiciar tal desenvolvimento;

b) existência ou inexistência de políticas públicas que amparem tal comunidade; 
c) valorização da LH no país acolhedor como herança cultural dos imigrantes e também dos próprios brasileiros, dentre outros imigrantes;

d) articulação diplomática entre os governos envolvidos, Brasil e Japão, para o desenvolvimento de eventos culturais que facilitem e estimulem a interação entre nativos e imigrantes;

e) ordem de aquisição da LH e da língua majoritária;

f) o período em que ocorre o insumo, comumente chamado de o "período crítico".

Esses são alguns dentre vários outros fatores que contribuem para a criação e o fortalecimento do PLH, embora não seja o objetivo desta pesquisa elencar tais fatores, mas analisar um recorte familiar para que, tomadas as devidas proporções e limitações, auxilie futuras pesquisas na área e, principalmente, lance um olhar atento às ações explícitas e implícitas que influenciam tais manifestações. Por conseguinte, discutimos na subseção as configurações de funcionamento de PLH, ou seja, qual a função da LH, permeada pelos objetivos e/ou expectativas que os participantes têm em mente quando do aprendizado desta.

\subsection{Configurações de funcionamento do PLH e o retorno à pátria}

Em consonância com o estudo de Mota (2004), boa parte dos imigrantes brasileiros que buscou na emigração melhores oportunidades econômicas e de trabalho alega residir temporariamente no Japão. No entanto, dentre as PM, a única que alegou ter pretensão de retorno ao Brasil foi a PM1, pois tanto a PM2 quanto a PM3 relataram não ter tais planos até o momento da entrevista. Na voz dos PF, o PF1 também foi o único a demonstrar interesse de retornar ao país, sendo o PLH claramente uma ferramenta válida e importante para atingir tal objetivo.

O PLH para a família da PM1 é considerado uma ferramenta fundamental para o futuro dos filhos, conquanto para a PM2 e para a PM3 tal objetivo não esteja claro, havendo um descompasso entre o objetivo do aprendizado e a expectativa desse aprendizado. Dentre os participantes, observamos diferentes configurações de funcionamento do PLH, tais como: 
a) elemento instrumental na vida escolar dos filhos quando do retorno e ou início do processo escolar brasileiro;

b) habilidade diferenciada para o futuro no mercado de trabalho e melhores oportunidades de emprego tanto no Japão quanto no Brasil pela proficiência em suas línguas;

c) manutenção dos laços familiares com o Brasil;

d) valorização da identidade brasileira por meio da $\mathrm{LH}$.

O PLH como elemento instrumental ocorre na família da PM1, pois o retorno ao Brasil já foi definido, e a língua portuguesa será o veículo de comunicação oficial, e não mais como uma LH restrita à família e à comunidade. Outro dado interessante nesse círculo familiar foi o fato de o PF1 ter manifestado expectativas de retornar à pátria dos pais e futuramente ingressar em uma instituição de ensino superior. Neste caso, as fronteiras linguísticas não representaram obstáculos ao desenvolvimento da $\mathrm{LH}$, pois com o insumo constante e diversificado os filhos da PM1 vivenciam a LH para além do núcleo familiar.

Independentemente do planejamento familiar e de suas motivações, as PM buscam caminhos alternativos para o desenvolvimento da LH. A PM3 acredita que o bilinguismo é uma habilidade diferencial para o futuro profissional de suas filhas, no entanto não prioriza a LH como uma ferramenta ou como característica identitária brasileira. Inferimos que a não conscientização do valor da língua materna possa estar diretamente refletida nas ações das filhas, que são pouco engajadas no projeto Construir.

$\mathrm{O}$ recorte da experiência da família da PM2 revela-nos um cenário completamente diferente das experiências da PM1 e da PM3, pois apesar de esta mãe revelar um profundo interesse no aprendizado de LH de suas filhas, não possui expectativas sobre tal desenvolvimento, embora a PF2 tenha revelado interesse em comunicar-se com outros brasileiros que não somente a mãe e familiares do Brasil. Inferimos, portanto, que a crença da PM2 é dissonante da das filhas, e suas ações diante destas não parece propiciar momentos de uso da LH para o desenvolvimento desta. Ao dizer isso não pretendo criticar as crenças e ou as ações de uma família e enaltecer as de outra, mas sim mostrar como as famílias lidam com a questão educacional e, com base nessa compreensão, refletir e elaborar 
práticas pedagógicas que as auxiliem a progredir em tal questão. Além disso, o período observado pode não retratar, de forma absoluta, a realidade familiar, pois, para conhecimento mais profundo dessas vivências, seria necessário um estudo etnográfico de longo prazo.

Dentre os participantes, é notável que cada família nutra de maneiras diferentes a herança linguística representada pelo PLH, e é natural a ocorrência da dissonância ou da convergência de crenças que, juntamente com os fatores contextuais da sociedade onde vivem, formam combinações complexas de ambientes de aprendizagem e desenvolvem, em maior ou menor intensidade, a LH. A leitura desses dados sugere que o planejamento familiar e a nutrição da línguacultura com oportunidades de uso diferenciadas levam a resultados relevantes para a proficiência da LH. O tripé "família-comunidadeprofessor" sugerido por Lico (2011) é também ponderado neste estudo de caso, pois a LH que parte do núcleo familiar e é expandida na sociedade, com ou até mesmo sem o intermédio de um professor, parece ter mais chances de êxito. Por fim, quando o objetivo do aprendizado é definido e quando há uma mínima confluência dos objetivos de pais e filhos, o desenvolvimento da $\mathrm{LH}$ pode ocorrer de modo satisfatório.

\subsection{As implicações do monolinguismo das mães e o bilinguismo dos seus filhos}

Conforme apontado anteriormente em estudo de Valdés (2001), na primeira geração de imigrantes ocorre a predominância do monolinguismo, enquanto as gerações vindouras tendem a incorporar a língua majoritária com mais frequência. De fato, inferimos, com base nos dados, que as PM como representantes da primeira geração de imigrantes da família também permanecem monolíngues em português e alegam baixa ou nenhuma proficiência na língua japonesa, embora esse fato não tenha sido comprovado por meio de avaliação de proficiência. Em contrapartida, seus filhos assimilam a nova línguacultura e distanciam-se, em alguns casos, como os da PF2 e da PF3, da língua de seus pais.

Busquei compreender aqui quais as relações que podem ser estabelecidas com base nesse monolinguismo com o bilinguismo dos filhos. As notas de campo da pesquisadora fornecem dados relevantes 
quanto às implicações do monolinguismo das mães. Primeiramente porque as PM parecem não estar inseridas completamente na sociedade japonesa, tanto pelas relações sociais serem limitadas aos brasileiros como também por não dominarem o código linguístico, consequentemente estão restritas socialmente dentro da comunidade brasileira no Japão. Do ponto de vista social, o círculo social das mães é bem distinto do círculo social dos filhos, embora haja alguma interação esporádica entre as crianças japonesas com os filhos de brasileiros fora do ambiente escolar, conforme explicação fornecida pela coordenadora do projeto de LH em questão.

Ora, se os laços sociais são geralmente criados no ambiente escolar, é possível afirmar que, com o tempo, cada vez mais essas crianças terão mais contato e afinidade com o modo de vida da sociedade japonesa ao continuarem residindo e estudando no Japão. Além desse possível distanciamento social, outro ponto importante a ser analisado é a participação das mães em reuniões escolares dos filhos. Tais reuniões são, geralmente, mediadas por um intérprete ou algum voluntário que faça a tradução japonês-português para que as mães possam compreender o que está sendo discutido. Em linhas gerais, o acompanhamento escolar dos filhos parece ocorrer de maneira conturbada, haja vista que as mães não compreendem o que se pede nas tarefas escolares, e a dinâmica de socialização entre casa-escola, casa-sociedade, dentre outras relações, dá indícios de que o desconhecimento da língua majoritária é problemático no curto e no longo prazos.

O monolinguismo das mães, portanto, parece interferir muito mais nos processos de socialização e convivência em diferentes domínios sociais do que, necessariamente, no desenvolvimento bilíngue dos filhos. O impedimento e/ou a dificuldade em participar ativamente da vida escolar dos filhos não puderam ser observados neste estudo de caso, mas compreendemos que são um fator limitante no acompanhamento escolar dos filhos. Além disso, ressaltamos a inversão da hierarquia pais-filhos quando os últimos são os facilitadores sociais em ambientes como prefeituras, lojas, mercados e outros locais onde é necessário não somente a compreensão da língua majoritária, mas a expressão oral e escrita.

Mota (2004) aponta que as situações nas quais os filhos assumem funções primordiais como porta-voz dos pais em serviços 
públicos acabam por empoderá-los, e isso pode causar desconforto tanto aos pais quanto aos filhos. Desse modo, os domínios sociais dos filhos tendem a distanciar-se do domínio social dos pais, que é geralmente restrito ao ambiente de trabalho e à comunidade brasileira. Compreendemos, com base na problemática supracitada, ser recomendável que os pais nutram as raízes brasileiras no seio familiar, mas também que estejam receptivos ao convívio social com os nativos do país onde residem e que, por meio do aprendizado da língua japonesa, possam ampliar os horizontes de suas relações e, principalmente, acompanhar o desenvolvimento escolar de seus filhos quando matriculados em redes escolares japonesas.

\section{Considerações finais}

A pesquisa em crenças é realizada, geralmente, com base nas crenças de professores e aprendizes no ensino de línguas, mas aqui levamos em conta o protagonismo dos pais, ou seja, os terceiros agentes envolvidos no processo educacional. A possibilidade de ter observado in loco o ensino-aprendizagem do PLH ajudou-me a delinear, ainda que de forma muito breve, o perfil dos aprendizes e de seus familiares e seus locais de ação. Busquei compreender como se identificam com a língua-cultura em questão e, em especial, suas crenças e ações referentes ao tema, de modo que o contexto vivenciado pelos participantes, verbal e não verbal, possibilitasse a (re)interpretação do lugar de ação.

Neste estudo operamos com base na abordagem contextual em crenças, ou seja, uma perspectiva que busca compreender a natureza subjetiva da aprendizagem de língua pelo contexto no qual estão imersos e, por meio de suas vozes, compreender o dizer e o agir em relação ao PLH. Alguns aspectos foram priorizados na tessitura deste artigo, sendo eles a expectativa de aprendizado dos participantes e o direcionamento de suas crenças, bem como a configuração do funcionamento do PLH nas famílias participantes e, por fim, as implicações do monolinguismo das PM e o bilinguismo dos PF. Tais temas foram escolhidos propositadamente, por representarem os pontos estratégicos da análise e da discussão dos dados. 
Inicialmente, verificamos que somente a nacionalidade desses brasileirinhos não traz garantia do senso de pertencimento ao grupo brasileiro, e que a escolha da língua japonesa como língua de preferência em suas comunicações diárias revela que a preferência de um código linguístico em detrimento de outro é uma marca de nossas escolhas identitárias, e ainda além, segundo Liebkind (apud SOUZA, 2010, p. 80), a língua pode se tornar o símbolo mais importante da identidade étnica. Em consonância parcial com o que assevera Montrul (2012), se o falante de LH não recebe suporte adequado durante o período escolar ele nunca terá a chance de desenvolver a língua mais adiante, no sentido de que não poderá desenvolvê-la na idade apropriada para atingir a competência próxima a de um nativo (considerando que tal nativo tenha competência comunicativa satisfatória da língua em questão).

Além da questão identitária, é importante destacar o oferecimento de insumo na língua-alvo ao aprendente. As ações dos pais diante da língua majoritária, neste estudo de caso, indicaram-nos que é possível lançar mão de iniciativas que estimulem tanto a $\mathrm{LH}$ quanto a majoritária e criar uma atmosfera bilíngue equilibrada e condizente com o insumo dado. Em outras palavras, o desenvolvimento do bilinguismo será mais exitoso se houver meios para tal desenvolvimento. À medida que os pais proporcionem insumo de qualidade, como em casa ou em projetos de LH, incentivo à leitura e apreciação de diversas obras midiáticas, os filhos terão cada vez mais contato com a diversidade da língua portuguesa, e isso possivelmente estimulará seu interesse em continuar e manter tal LH. Os falantes de LH precisam de motivação para manter e desenvolver sua LH além daquilo que adquiriram em casa (MONTRUL, 2012, p. 7, tradução nossa $^{7}$ ).

Compreendo que a pesquisa em LH é recente, e o PLH entre brasileiros no exterior é um tema ainda em construção, carecendo de políticas e iniciativas públicas que propiciem tal desenvolvimento. Além disso, a amostra de dados desta pesquisa não é suficiente para compreender o fenômeno migratório e a questão educacional do PLH

\footnotetext{
${ }^{7}$ Trecho original: "Heritage speakers need motivation to maintain and develop their heritage language beyond what they acquired at home" (MONTRUL, 2012, p.7).
} 
dos brasileiros no Japão. Todavia, esse recorte parece nos indicar a importância do estabelecimento de uma relação de equilíbrio entre a língua majoritária e a língua de herança.

Outro ponto chave da discussão acerca do ensinoaprendizagem do PLH entre a comunidade brasileira no Japão é o fato de que, na maioria dos casos, os pais trabalham exaustivamente nas fábricas e nas linhas de montagem de grandes empresas e passam mais de dez horas realizando atividades braçais com poucas garantias trabalhistas e assistência governamental, seja esta japonesa seja brasileira. O excesso de carga horária no trabalho, a desvalorização da força de trabalho imigrante e, consequentemente, a escassez de tempo e cuidados com a própria saúde mental e física podem gerar uma série de obstáculos para esses pais acompanharem a vida escolar de seus filhos, que, acolhidos apropriadamente ou não nas escolas japonesas, tendem a ser incorporados à sociedade dominante devido à pressão cultural sofrida em tais escolas (cf. TSUDA, 2003).

Por fim, acredito que do ponto de vista político seja extremamente relevante mais estudos em relação ao PLH, levando-se em consideração que a manutenção e a expansão de uma língua são um movimento político. A criação de um centro cultural brasileiro poderia, por exemplo, suprir a demanda inicial de atividades culturais não somente para brasileiros, mas interessados em geral pela língua-cultura brasileira em território japonês. Além disso, cabe ao governo brasileiro contribuir para a valorização e a difusão da nossa língua, sendo, teoricamente, um dos objetivos prioritários da Divisão de Promoção da Língua Portuguesa (DPLP), integrante do Departamento Cultural do Itamaraty. Finalizo este artigo ratificando as propostas já indicadas na IV Conferência Brasileiros no Mundo (2014) para a promoção do PLH entre as comunidades brasileiras no exterior, sendo elas:

102. Disponibilização de exemplares de publicações expostas em feiras

internacionais do livro para entidades brasileiras no exterior que lidem com ensino de Português como língua de herança $(F B N)$.

121. Valorização e apoio para capacitação de educadores $e$ professores de Português como Língua de Herança no exterior, 
com continuação dos cursos realizados pelo Departamento Cultural do MRE (MRE, MEC).

127. Fomento ao contato, ao intercâmbio e à troca de experiências entre as iniciativas que promovem o Português como Língua de Herança no mundo (MEC, MRE).

170. Envio de material didático e paradidático a instituições de ensino de Português como Língua de Herança no exterior (MEC, FNDE, MinC).

Oxalá possamos celebrar, num futuro próximo, a concretização de tais propostas e contar com futuras pesquisas que abordem identidade, letramento, motivação e interculturalidade do PLH em contextos como da presente pesquisa, haja vista que a disseminação das raízes culturais dos pais aos filhos envolve vínculos afetivos e identitários e, assim, possivelmente possamos compreender e atuar com mais dinamismo e eficácia. Além disso, urge a pesquisa sobre políticas linguísticas, em especial sobre o PLH, além da integração de pesquisas na área de sociolinguística, psicolinguística, antropologia, dentre outras, que nos auxiliem a compreender e a aprimorar o fenômeno estudado aqui. Há muito ainda por fazer e pesquisar, mas cremos ter dado um passo importante rumo ao desenvolvimento do PLH no Japão.

\section{Referências}

ABRAHÃO, Maria. H. V. Crenças e ensino de línguas: foco no professor, no aluno e na formação de professores. Campinas: Pontes Editores, 2006.

BARCELOS, Ana. M. F. Cognição de professores e alunos: tendências recentes na pesquisa de crenças sobre o ensino e aprendizagem de línguas. In: BARCELOS, A. M. F.; ABRAHÃO, M. H. V. (Orgs.). Crenças e ensino de línguas: foco no professor, no aluno e na formação de professores. Campinas: Pontes Editores, 2006. p. 15-42.

KRAMSCH, Claire. J. Language and culture. Oxford: Oxford University Press, 1998. 
LEE, Jin. S.; SHIN, Sarah. J. Korean heritage language education in the United States: the current state, opportunities, and possibilities. Heritage Language Journal, Baltimore County, v. 6, n. 2, p. 153-172, 2008.

LICO, Ana. L. Ensino do português como língua de herança: prática e fundamentos. Revista SIPLE, v. 2, n. 1, mai-2011. Disponível em: $<$ http://www.siple.org.br/index.php?option=com_content\&view=articl e\&id=177:2- ensino-do-portugues-como-lingua-de-heranca-praticaefundamentos $\&$ catid $=57$ :edicao- $2 \&$ Itemid $=92>$. Acesso em: 02 nov. 2015.

MARCUSCHI, Luiz A. Análise da conversação. São Paulo: Ática, 2003.

MENDES, Edleise. Vidas em português: perspectivas culturais e identitárias em contexto de português língua de herança. Revista do Instituto Internacional da Língua Portuguesa, IILP, Cabo Verde, 2012.

MEXT, Ministério da Educação Ciência e Tecnologia. Sobre a situação das línguas estrangeiras em contexto ginasial japonês do ano de 2013 até atualidade. Disponível em: <http://www.mext.go.jp/component/a_menu/education/detail/_icsFile s/afieldfile/2015/ 04/09/1323948_03_2.pdf>. Acesso em: 01 mar. 2016.

MONTRUL, Silvina. Is the heritage language like a second language? Eurosla Yearbook, v. 12, p. 1-29, 2012. Disponível em: <http://dx.doi.org/10.1075/eurosla.12.03mon>. Acesso em: 01 mar. 2016.

MORONI, Andreia; GOMES, Juliana. A. O português como língua de herança hoje e o trabalho da associação de pais de brasileirinhos na Catalunha. Revista de Estudios Brasileños, Salamanca, v. 22, n. 2, p. 21-35, 2015. 
Um estudo de caso sobre o PLH...

MOTA, Kátia. S. Aulas de português fora da escola: famílias imigrantes brasileiras, esforços de preservação da língua materna. Cadernos Cedes, Campinas, v. 24, n. 63, p. 149-163, 2004.

VALDÉS, Guadalupe. Heritage language students: profiles and possibilities. In: PEYTON, J.; RANARD, D.; MCGINNIS, S. (Eds.). Heritage languages in America: preserving a national resource. Washington, DC: Center for Applied Linguistics and Delta Systems, 2001. p. 37-77.

YONAHA, Tábata. Q. O PLH no contexto de emigrantes brasileiros no Japão: crenças e ações de mães brasileiras. 2016, 137 f. Dissertação (Mestrado em Linguística Aplicada) - Instituto de Letras, Universidade de Brasília, 2016. 
Tábata Yonaha; Yuki Mukai

\section{ANEXO I}

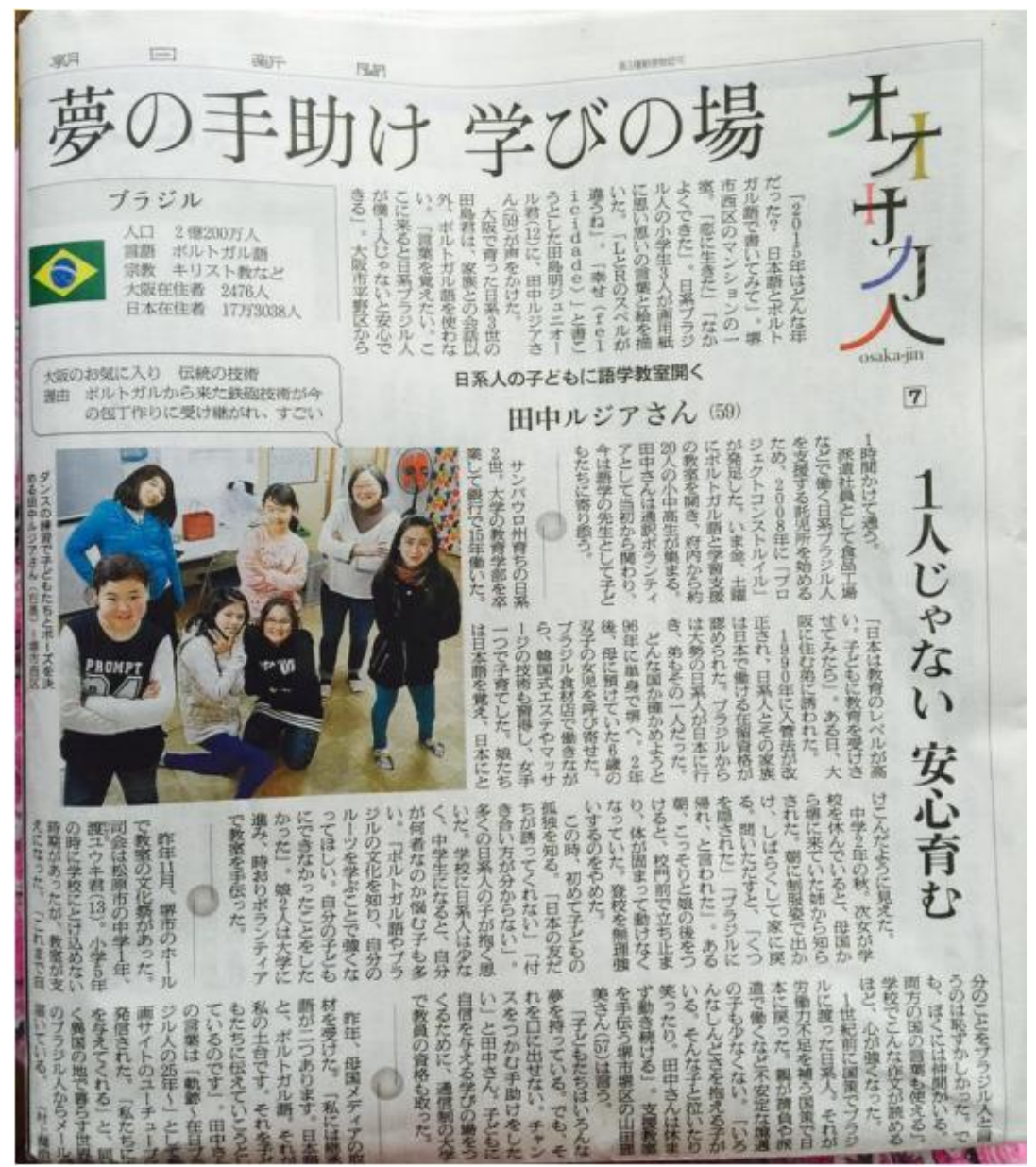

Recebido em: 19/10/2017 Aceito em: 15/02/2018

Title: A case study about Portuguese as a Heritage Language in Suzuka and Sakai, Japan 